\title{
EFFECT OF HEXAMETHYLENEDIAMINE FUNCTIONALIZATION OF CNT ON EPOXY RESIN MECHANICAL PROPERTY
}

\author{
W. FRANCISCO ${ }^{1}$, F. V. FERREIRA ${ }^{1}$, E. V. FERREIRA ${ }^{2}$, L. S. CIVIDANES ${ }^{1}$, A. R. \\ COUTINHO $^{3}$ and G. P. THIM ${ }^{1}$ \\ ${ }^{1}$ Instituto Tecnológico de Aeronáutica, Divisão de Ciências Fundamentais \\ ${ }^{2}$ Universidade Federal de Juiz de Fora, Departamento de Estatística \\ ${ }^{3}$ Universidade Metodista de Piracicaba, Laboratório de Materiais Carbonosos \\ E-mail to contact: wesley-francisco@hotmail.com
}

\begin{abstract}
Carbon nanotubes (CNTs) were treated using acids and Hexamethylenediamine (HMDA). The presence of acid and amine chemical groups on the CNTs surface was confirmed by X-ray Photoeletron Spectroscopy (XPS). The nanocomposites were produced with epoxy resin and modified CNTs. Vickers hardness tests were carried out on the composites and neat resin. Results showed an increase in the sample hardness prepared with functionalized CNTs. This phenomenon is due to the compatibility between modified CNTs and epoxy resin is much higher than between bare CNTs and epoxy resin. This higher compatibility is related to the strong interfacial interaction between the functionalized CNTs and the polymer.
\end{abstract}

\section{INTRODUCTION}

Carbon nanotubes (CNTs) were discovered in 1991 by Iijima and they have attracted a worldwide attention due to their outstanding thermal, electronic and mechanical properties (Shin et al., 2013; Wang and Liew, 2015). Among the diverse potential applications, one of the most promising of them is the use CNTs as reinforcing fillers (Shen et al., 2007; Bhuiyan et al., 2013).

However, CNT application as polymer filler has been hindered by some difficulties in the dispersion and low adhesion to matrix (Disfani and Jafani, 2013). These facts limit significantly potential applications of CNT, since it CNT tends to agglomerate due to Van der Waals force (Ratna et al., 2013). Researchers have added functional groups on the CNT surface to improve the dispersion. Many CNT functionalizations have been reported, such as carboxyl and amino groups, and these functionalizations increased the CNT dispersion (Wang et al, 2007).

The focus of this paper is to evaluate the effect of carboxyl and amino functionalization of CNTs on the mechanical property of the epoxy resin filled with modified CNTs. The functionalized CNTs were characterized by X-ray Photoelectron Spectroscopy (XPS). Moreover, it was added functionalized CNTs to the polymer matrix and the Vickers hardness tests on the neat resin, composite with pristine CNT and modified CNTs was carried out. 


\section{EXPERIMENTAL}

\subsection{Materials}

The carbon nanotubes samples used in this work were acquired from Instituto Nacional de Pesquisas Espaciais (LAS/INPE) and prepared by a chemical vapor deposition method, as described in a previously study (Antunes et al., 2011). CNT was purified, performed an oxidative acid treatement and then the functionalization step was performed (Jin et al., 2011). The functionalized sample was labeled as CNT-H.

\subsection{Surface modification and functionalization of CNTs}

A quantity of CNT-H $(0.8 \mathrm{~g})$ was added to $90 \mathrm{ml}(\mathrm{v} / \mathrm{v} 3: 1)$ of sulfuric acid $\left(\mathrm{H}_{2} \mathrm{SO}_{4}\right.$, Merck, 98\%) and $30 \mathrm{ml}$ of nitric acid $\left(\mathrm{HNO}_{3}\right.$, Vetec, $\left.70 \%\right)$, in an ultrasonicator bath with power of $225 \mathrm{~W}$ for $6 \mathrm{~h}$ at room temperature. This sample was called CNT-Ac.

The Sample CNT-Ac $(0.3 \mathrm{~g})$ was dispersed in $150 \mathrm{ml}$ of Hexamethylenediamine (HMDA, $\mathrm{NH}_{2}\left(\mathrm{CH}_{2}\right)_{6} \mathrm{NH}_{2}$, Aldrich, 70\%). The mixture was maintained under stirring and heating at $100{ }^{\circ} \mathrm{C}$ for 4 days. Then, the modified CNTs were filtered through $0.45 \mu \mathrm{m}$ polytetrafluorethilene (PTFE) and they were named as CNT-HMDA. Figure 1 presents an illustration of surface modification.

Figure 1 - Surface modification and functionalization.

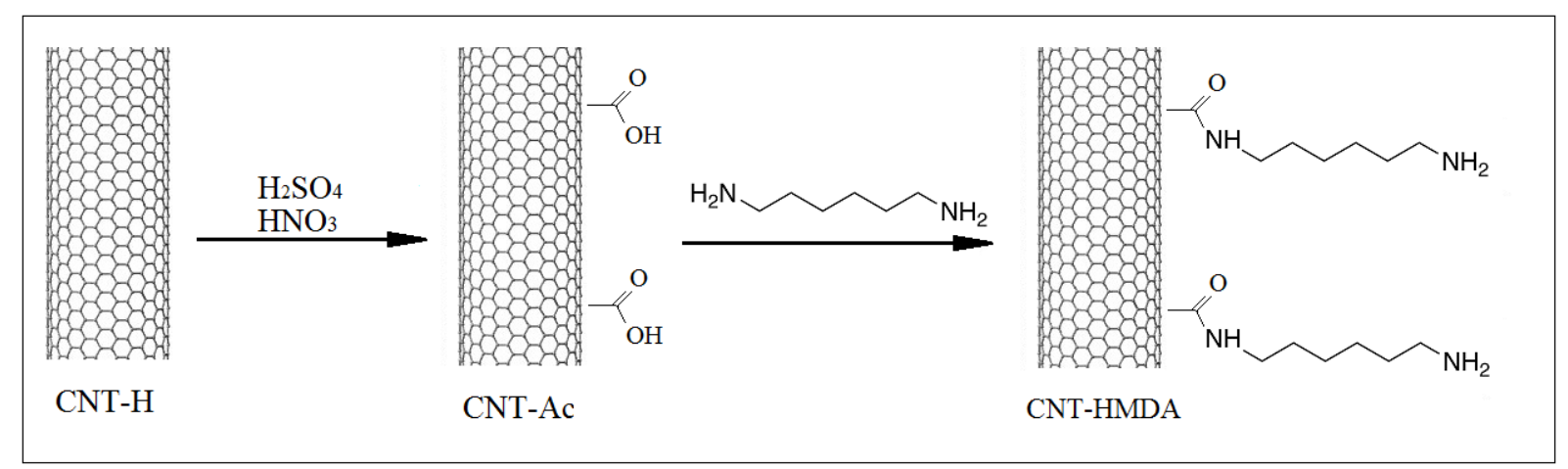

\subsection{Preparation of nanocomposites and neat resin}

The nanocomposites (CNT-H/epoxy, CNT-Ac/epoxy and CNT-HMDA/epoxy) and the neat resin (Epoxy) were synthesized with epoxy resin diglycidyl ether of bisphenol A (DGEBA), diaminodiphenylmethane (DDM) and $0.2 \% \mathrm{CNT}$.

\subsection{Characterization and measurements}

X-ray Photoeletron Spectroscopy (XPS) analysis of the CNT samples was carried out on a commercial spectrometer (UNI-SPECS UHV), with $\mathrm{Mg} \mathrm{K} \alpha$ line $(\mathrm{h} v=1253.6 \mathrm{eV})$ and a pass energy set at $10 \mathrm{eV}$. Vickers hardness measurements were carried out on samples in a diamond Vickers indenter Tester FM-700, where a $0.2 \mathrm{Kgf}$ load was applied for 10 seconds. The hardness value HV (in GPa) was calculated from the indentation load and the diagonal of 
the Vickers imprint. Thirty two indents were made on each surface keeping an appropriate distance from the sample edges and between indentation marks, avoiding boundary effects (confidence intervals: 95\%). The entire computational environment was developed in $\mathrm{R}$ (a statistical computational and graphical environment) program (R Development Core Team, 2012).

\section{RESULTS AND DISCUSSION}

Figure 2a-c shows the XPS analysis on the samples CNT-H, CNT-Ac and CNTHMDA. The deconvoluted XPS C1s spectrum shows a main component at $284.4 \mathrm{eV}$, which is related to aromatic carbon bonding $\left(\mathrm{C}-\mathrm{C} \mathrm{sp}^{2}\right)$ from the hexagon walls of the CNTs. The peak centered at $285.2 \mathrm{eV}$ refers to $\mathrm{C}-\mathrm{CH} \mathrm{sp}{ }^{3}$ bond, which is related to defects in the aromatic structure and that ranging 285.2-285.9 eV may be related to hydrocarbon from surface contamination. In addition, other peaks may be assigned to chemical bondings of C-O at $286.3 \mathrm{eV}, \mathrm{C}=\mathrm{O}$ at $287.7 \mathrm{eV}$ and $\mathrm{O}-\mathrm{C}=\mathrm{O}$ at $289 \mathrm{eV}$. The plasmon $\pi-\pi^{*}$ peak has placed at 291 $\mathrm{eV}$. The deconvoluted XPS N1s spectrum (Figure 2d) shows three peaks: $\mathrm{C}^{-\mathrm{NH}_{2}}$ at $399.1 \mathrm{eV}$, $\mathrm{N}-\mathrm{C}$ at $400.3 \mathrm{eV}$ and $\mathrm{N}-\mathrm{O}$ at $402 \mathrm{eV}$.

Figure 2 - XPS spectra regarding (a) CNT-H C1s, (b) CNT-Ac C1s, (c) CNT-HMDA C1s and (d) CNT-HMDA N1s.
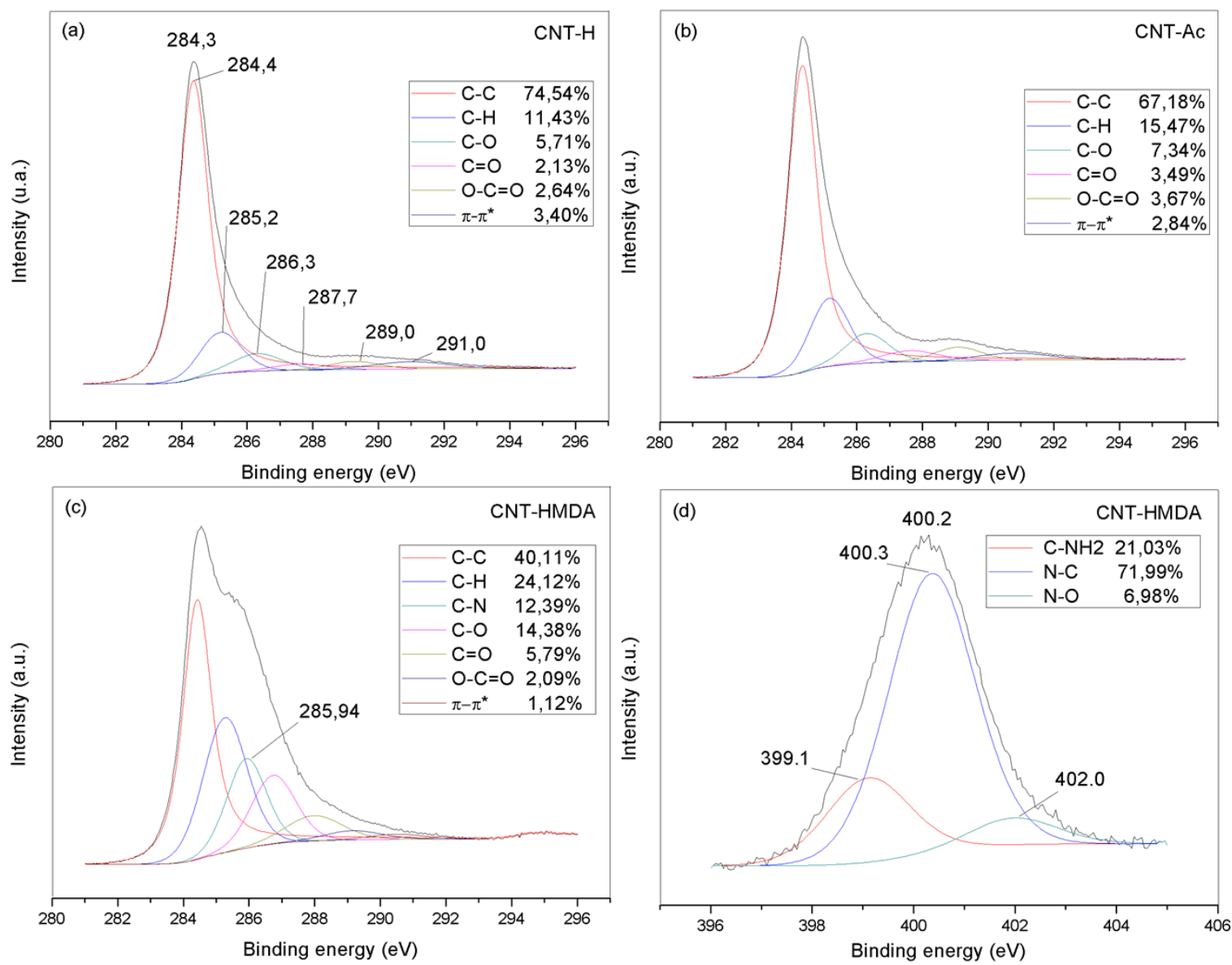
Figure 2a-b showed that sample CNT-Ac has a higher percentage of $\mathrm{C}-\mathrm{O}, \mathrm{C}=\mathrm{O}$ and $\mathrm{O}-\mathrm{C}=\mathrm{O}$ groups than sample $\mathrm{CNT}-\mathrm{H}$, which indicates the presence of carboxyl group on the CNT-Ac surface. In addition, Figure $2 c$ shows the presence of C-N chemical group, indicating the presence of nitrogenated functional group on the CNT surface. The deconvoluted XPS C1s spectra, Figure 2a-b-c, shows that the amount of chemical groups related to peak at $285.2 \mathrm{eV}\left(\mathrm{C}-\mathrm{CH} \mathrm{sp}{ }^{3}\right)$ increase in the following order: CNT-H < CNT-Ac < CNT-HMDA. This increase is related to an increase in the defects on the CNTs wall, which contributes for adding functional groups on the CNT-Ac and CNT-HMDA surfaces (Figure 2b-c) (Komarova et al., 2015).

Figure 3 shows the distribution of hardness results. Y-axis represents the ordered data and $\mathrm{x}$-axis is normal quantile. It is noticed that the hardness measurements are randomly distributed on the confidence intervals, where the data normality ( $p$-value $<0.001$ ) was admitted.

Figure 3 - Normal QQ Plot. (a) Epoxy, (b) CNT-H/epoxy, (c) CNT-Ac/epoxy and (d) CNT-HMDA/epoxy.
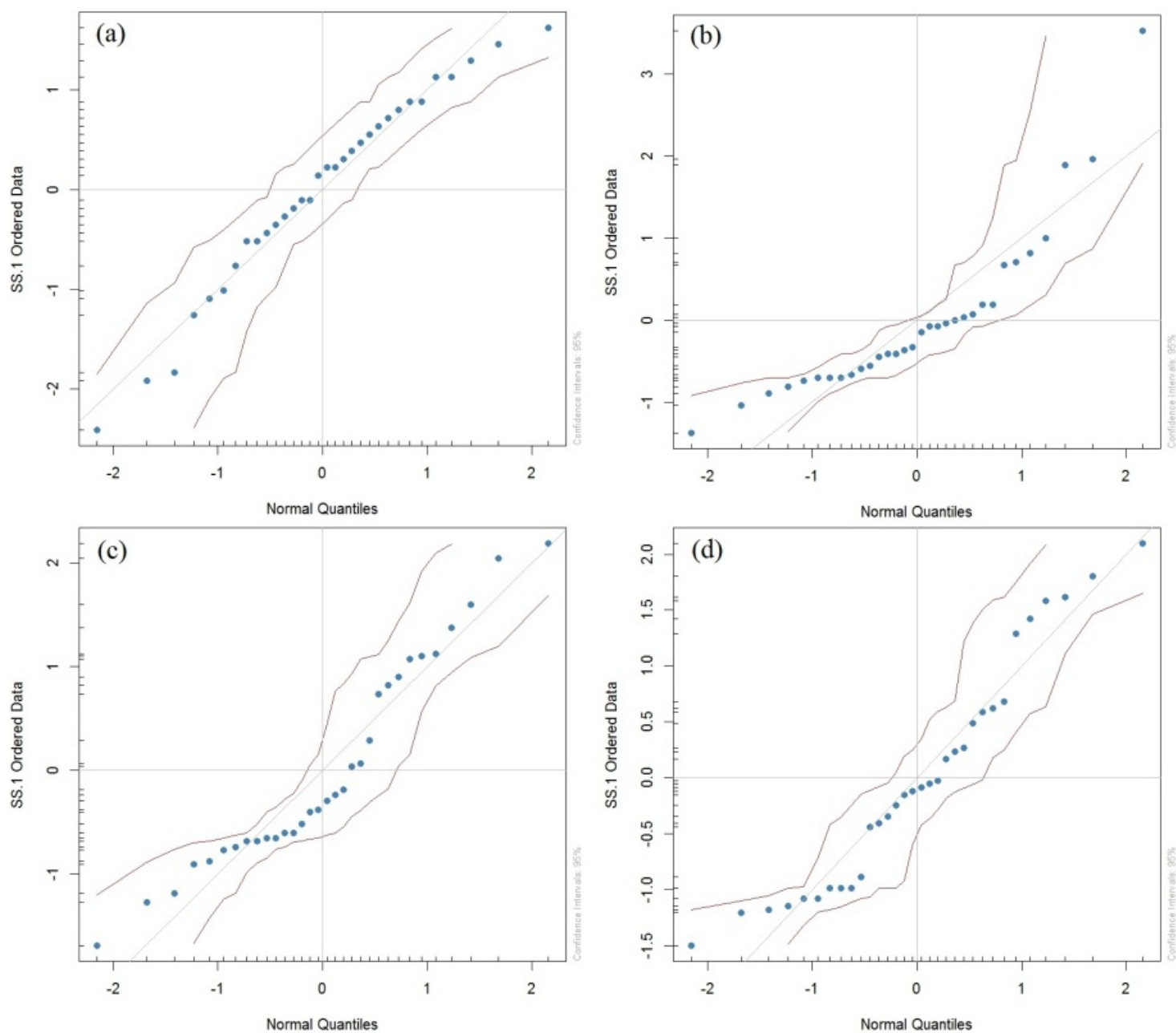
Figure 4 shows the Box-Plot of different composites $(\mathrm{CNT}=0.2$ wt.\%). It is noticed from Figures $a-b$ that the adding of CNT in the resin without surface modification produces a slight increase in average hardness from 21.33 to $21.69 \mathrm{HV}$ (significantly same values; pvalue $=0.487)$. It is known that functionalized CNTs have more disorganized microstructure compared to pristine CNT, which lead to greater dispersion of CNTs, hence has better interfacial bonding with the polymer matrix (Cividanes, 2012). In addition, Figure 4c-d showed an increase in the average hardness of about $30 \%$ in the composite prepared with CNT-Ac. Afterwards in the sample CNT-HMDA, the hardness increased from 27.95 to 29.56 (values statistically different; $p$-value $=0.06$ ). It may be attributed to the presence of amine functional groups onto CNT surfaces (Liu and Wagner, 2005; Martinez-Hernandez et al., 2010; Gkikas and Paipetis, 2015).

Figure 4 - Vickers hardness of the samples: Epoxy, CNT-H/epoxy, CNT-Ac/epoxy and CNT-HMDA/epoxy

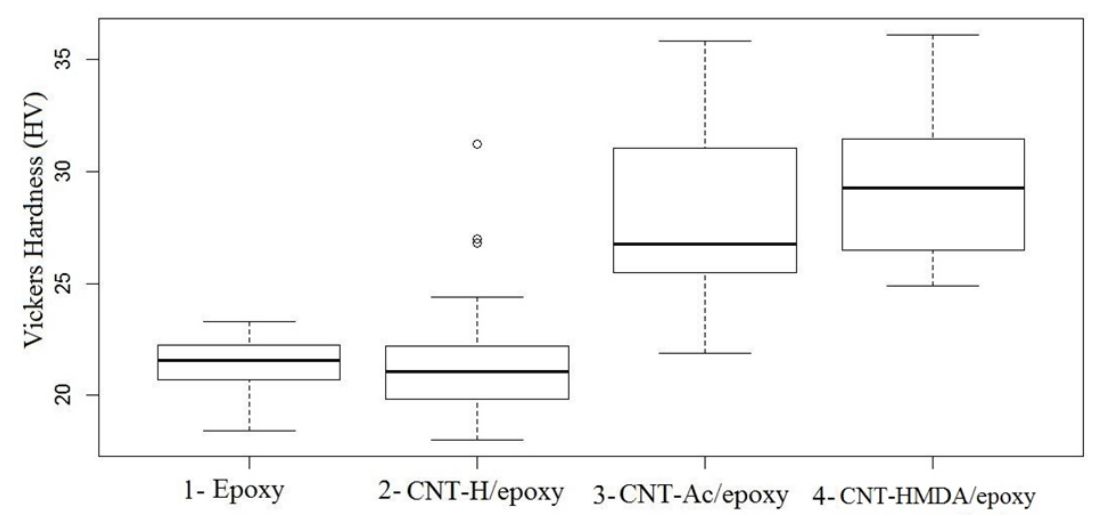

In the other hand, it appears that CNT additions increase significantly the composite sample variability in the hardness ( $p$-value $<0.001)$. The high variability of the hardness results may be attributed to CNTs dispersion in the polymer matrix, which can affect the final nanocomposite properties (Song and Young, 2005; Bal and Samal, 2006; Cividanes et al., 2012).

\section{CONCLUSIONS}

The CNTs functionalized with acid and HMDA was submitted to XPS analysis and it was observed the presence of the carboxyl and amine groups, which confirms the functionalization success. The results has shown the neat resin and CNT-H composite presented almost the same hardness, although, the functionalization has increased the CNT-Ac and CNT-HMDA composites hardness, where the amine functionalized composite has presented the highest hardness value among the all composites.

\section{ACKNOWLEDGEMENTS}

The authors acknowledge CNPq (Grant 141197/2014-5) and FAPESP (Grant 2013/20218-0) for financial support, and LAS/INPE and LEFE/UNESP for collaboration.

\section{REFERENCES}


BAL, S.; SAMAL, S. S.. Influence of dispersion states of carbon nanotubes on mechanical properties of epoxy nanocomposites. Recent trends in mechatronics, nanotechnology and robotics, v.15-16, p.322-328, 2006.

BHUIYAN, A.; PUCHA, R. V.; WORTHY, J.; KAREVAN, M.; KALAITZIDOU, K.. Defining the lower and upper limit of the effective modulus of CNT/polypropylene composites through integration of modeling and experiments. Composite Structures, v.95, p.80-87, 2013.

CIVIDANES, L.; BRUNELLI, D.; ANTUNES, E.; CORAT, E.; SAKANE, K.; THIM, G. Cure study of epoxy resin reinforced with multiwalled carbon nanotubes by raman and luminescence spectroscopy. Journal of Applied Polymer Science., v.27,p. 544-553, 2012.

DISFANI, M. N.; JAFANI, S. H.. Assessment of intertube interactions in diferent functionalized multiwalled carbon nanotubes incorporated in a phenoxy resin. Polymer Engineering and Science, v.53, p.168-175, 2013.

GKIKAS, G.; PAIPETIS, A. S.. Optimization analysis of the reiforcement effect of carbon nanotubes in a tipical matrix system. Meccanica, v.50, p.461-478, 2015.

IIJIMA, S. Helical microtubules of graphitic carbon. Nature (London)., v.354,p. 56-58, 1991. KOMAROVA, N. S.; KRIVENKO, A. G.; RYABENKO, A. G.; NAUMKIN, A. V.; MASLAKOV, K. I.; SAVILOV, S. V.. Functionalization and defunctionalization of single walled carbon nanotubes: electrochemical and morphologic consequences. Journal of electoanalitical chemistry, v.738, p.27-34, 2015.

LIU, L.; WAGNER, H.D.. Rubbery and glassy epoxy resins reinforced with carbon nanotubes. Composite Science and Technology, v.65, p.1861-1868, 2005.

MARTINEZ-HERNANDEZ, A.L.; VELASCO-SANTOS, C.; CASTANO, V.M. CNTs composites: processing and mechanical properties. Current Nanoscience, v.6, p.12-39, 2010.

R Development Core Team. A Language and Environment for Statistical Computing, 2012.

RATNA, D.; JAGTAP, S. B.; RATHOR, R.; KUSHWAHA, R. K.; SHIMPI, N.; MISHRA, S. N.. A comparative studies on dispersion of multiwall carbono nanotubes in poli (ethylene oxide) matrix using dicarboxylic acid and amino acid based modifiers. Polymer Composites, v.34, p.1003-1011, 2013.

SAEB, M. R.; NAJAFI, F.; BAKHSHANDEH, E.; KHONAKDAR, H. A.; MOSTAFAIYAN, M.; SIMON, F.; SCHEFFLER, C.; MÄDER, E.. Highly curable epoxy/MWCNTs nanocomposites: An effective approach to functionalization of carbon nanotubes. Chemical Engineering Journal, V.259, p.17-125, 2015.

SHEN, J.; HUANG, W.; WU, L.; HU, Y.; TE, M.. The reiforcement role of diferent aminofunctionalized multi-walled carbon nanotubes in epoxy nanocomposites. Composites science and technology, v.67, p.3041-3050, 2007.

SHIN, H.; YANG, S.; CHANG, S.; YU, S.; CHO, M.. Multiscale homozanization modeling for thermal transport properties of polymer nanocomposites with Kapitza thermal resistance. Polymer, v.54 p.1543-1554, 2013.

SHIREN WANG A, *, RICHARD LIANG B, BEN WANG B, CHUCK ZHANG . Epoxideterminated carbon nanotubes. Carbon 45 (2007) 3042-3059.

SONG, Y. S.; YOUNG, J. R.. Influence of dispersion states of carbon nanotubes on physical properties of epoxy nanocomposites. Carbon, v.43, p.1378-1385, 2005.

WANG, J. F.; LIEW, K. M.. On the study of elastic properties of CNT-reiforced composites based on element-free MSL method with nanoscale cylindrical representative volume element. Composite strutures, v.124, p.1-9, 2015. 